\title{
Distributions and controls of sediment organic carbon in hadal trenches
}

\author{
WENJIE XIAO ${ }^{1}$, YUNPING XU ${ }^{2}$, JIASONG FANG ${ }^{2}$ AND \\ RONNIE N GLUD ${ }^{3}$ \\ ${ }^{1}$ Southern University of Science and Technology \\ ${ }^{2}$ Shanghai Ocean University \\ ${ }^{3}$ University of Southern Denmark \\ Presenting Author: wjxiaocug@126.com
}

The hadal trenches having water depth of 6 to $11 \mathrm{~km}$ is the deepest realm of the ocean. Due to the challenges of sampling and observation at extremely deep environments, the biogeochemical process of sedimentary organic carbon (OC) in hadal trenches is poorly known. Here, we investigate in the geochemical and sedimentological compositions of multiple sediment cores from the New Britain Trench and Bougainville Trench varying in water depth of 1560 to $8900 \mathrm{~m}$. The combination of our results and literature data reveals that the hadal trenches behave like a deep oceanic trap for OC. With the trench interior, sediment OC is heterogeneous, which is affected by terrestrial input, shelf width, sediment grain size, seismic activity and local topography. The proximity to land masses, relatively high sedimentation rate and abundant OC content lead us to propose that the hadal trenches may be a significant, currently undocumented sink for OC which is helpful for resolving the long-term unresolved puzzle on missing of terrestrial $\mathrm{OC}$ in the ocean. 